\title{
BMJ How are drug regimen changes during Open hospitalisation handled after discharge: a cohort study
}

\author{
Kirsten K Viktil, ${ }^{1,2}$ Hege Salvesen Blix, ${ }^{3,4}$ Anne Katrine Eek, ${ }^{4,5}$ \\ Maren Nordsveen Davies, ${ }^{4,6}$ Tron A Moger, ${ }^{7,8}$ Aasmund Reikvam ${ }^{4}$
}

To cite: Viktil KK, Blix HS, Eek AK, et al. How are drug regimen changes during hospitalisation handled after discharge: a cohort study. BMJ Open 2012;2:e001461. doi:10.1136/bmjopen-2012001461

- Prepublication history for this paper are available online. To view these files please visit the journal online (http://dx.doi.org/10.1136/ bmjopen-2012-001461).

Received 28 May 2012 Accepted 18 October 2012

This final article is available for use under the terms of the Creative Commons Attribution Non-Commercial 2.0 Licence; see http://bmjopen.bmj.com

For numbered affiliations see end of article

\section{Correspondence to} Dr Kirsten K Viktil; kirsten.viktil@diakonsyk.no, kirstkv@farmasi.uio.no

\section{ABSTRACT}

Objectives: To investigate drug regimen changes during hospitalisation and explore how these changes are handled after patients are transferred back into the care of their general practitioners (GPS).

Design: Cohort study.

Setting: Patients in this multicentre study had undergone at least one change in their drug regimens at discharge from the general medicine departments at six hospitals in Norway. These changes were altered doses, discontinuation of drugs or start of new drugs. Clinical pharmacists visited the patients' GPs 4-5 months after patient discharge and recorded any additional drug regimen changes.

Results: In total, 105 patients (mean age 76.1 years, $54.3 \%$ women) completed the study. On average, they used 5.6 drugs at admission (range $0-16$ ) and 7.6 drugs at discharge (range 1-17). On average, 4.4 drug changes per patient (SD 2.7, range 1-16) were made at the hospital, and 3.4 drug changes per patient (SD 2.9, range 0-14) within 4-5 months of discharge. Of the 465 drug changes made in hospital, 153 were changed again after discharge (mean 1.5 per patient, SD 1.8, range $0-13)$. The drug regimens of 90 of these 105 patients were changed after discharge. The $\mathrm{OR}$ for extensive drug changes after discharge ( $\geq 4$ changes) increased significantly with the number of drugs used at discharge from hospital $(\mathrm{OR}=1.29,95 \% \mathrm{Cl} 1.04$ to 1.59$)$. Only 68 of 105 discharge notes contained complete drug lists, and only 24 of the discharge notes were received by the GPs within 7 days.

Conclusions: In addition to the extensive changes in drug regimens during hospitalisation, almost equally extensive changes were made in the initial months after discharge. Surveillance of drug regimens is particularly necessary in the period immediately after hospital discharge.

\section{INTRODUCTION}

Patients have contact with different parts and levels of the healthcare system throughout their lives. When a patient is transferred between different levels of care, it is crucial that his/her needs are communicated well, and not least is it important that the patient's

\section{ARTICLE SUMMARY}

Article focus

- Investigation of patients' drug regimen changes instituted during hospitalisation.

- Handling of these drug changes after transfer of the patients back into the care of their general practitioners (GPS).

Key messages

- Extensive changes in patients' drug regimens were made during their hospital stays and almost equally extensive changes were undertaken after the patients were transferred back into the care of their GPs.

- Discharge notes from the hospital to GPs were received late and often included incomplete drug lists.

- Surveillance of drug regimens is particularly necessary in the period immediately after hospital discharge.

Strengths and limitations of this study

- The design of the study is a strength; the hospital pharmacist visited the GPs in their practices and interviewed them about the drug regimen of each individual patient.

- A limitation of the study is that although categories of drug changes were investigated, the justification for the individual changes was not evaluated.

drug regimen is correctly and accurately reported. Hospitalisation and, possibly even more so, discharge from hospital are critical junctures at which failures in communication might occur.

Changes in drug regimens undertaken during hospitalisation have been investigated to some degree but they have barely been examined in relation to the transfer of patients into the care of their general practitioners (GPs). ${ }^{1-7}$ However, in a study based on a prescription database, it was found that hospitalisation exerted a marked influence on changes in drug therapy in ambulatory care. ${ }^{7}$ In a study of patients from one single 
general practice, medication changes were reported for patients followed to hospital and back into primary care. ${ }^{4}$ In two studies, patients were interviewed after discharge, but the GP's role was not explored. ${ }^{5}{ }^{6}$ This issue is important, because changes made in hospital must often be followed by the patient's GP. This pertains to dose increases or dose reductions and drug discontinuations after definite time periods, and laboratory tests are sometimes required to evaluate drug therapies properly. Poor communication about drug regimens could have negative consequences for patients, and probably even contribute to increased mortality. ${ }^{5}$

Drug changes that occur when patients are transferred between levels of care are not easily studied. However, in this study, pharmacists from the hospitals visited the patients' GPs in their practices. The aim of this study was to investigate the drug regimen changes instituted during hospitalisation and how these changes are handled after the patients are transferred back into the care of their GPs.

\section{METHODS}

Design and patients

This multicentre study was approved by the Norwegian Regional Committee for Medical Research and the Norwegian Social Science Data Services. During three 2-week periods in 2008 and 2009, clinical pharmacists included patients from the general internal medicine departments of six different hospitals in Norway. Patients eligible for the study were aged 18 years or more, and had experienced at least one change in their drug list at discharge compared with the drug regimen they had at admission to hospital. The changes could be dosage alterations, discontinuation of a drug or start of a new drug. Changes in the doses of drugs given in variable and individualised doses, such as warfarin and insulin, were not recorded as drug changes, nor were the substitution of a generic drug recorded as a change. Temporary drug changes in hospital or temporary changes in doses during hospital stay were not recorded, because our aim was to investigate the follow-up of the medications after discharge. The eligible patients were consecutively included in the three 2-week study periods. Re-admitted patients were not included. The patients gave their written informed consent to participation in the study, and also permission for the pharmacists to visit their GPs after their discharge to assess how their medications had been handled after discharge. Almost all eligible patients admitted to the participating wards accepted to take part in the study and we estimated that more than $95 \%$ of the eligible patients were actually included.

\section{Data collection}

A standard data recording form was used. In a pilot study, the form was tested and found applicable for our study purpose. In hospital, the pharmacists recorded the patient's sex, age, length of stay, drugs and doses usedboth regularly used drugs and drugs used as requiredat hospital admission and at discharge. The patients' admission drug regimen, obtained from the medical charts worked out by the physicians at the patients' admission to hospital, was entered into the standard form. The drugs were recorded by trade name and classified according to the anatomical therapeutic chemical (ATC) classification system. ${ }^{8}$ Some specific factors that may influence drug use, and risks associated with drug use, were also recorded. These factors have been investigated by our group in other studies; details are given elsewhere. $^{9}$ They are, by nature, a composition of pharmacological, clinical and patient-related factors, here called clinical/pharmacological risk factors. The following were recorded: laboratory data (creatinine clearance, liver function tests and electrolytes), blood pressure and the presence of heart failure, renal failure or metabolic diseases (diabetes mellitus and thyroid disorders). The data were recorded based on the information in the patient's medical record.

The discharge note for each patient was collected at the hospital. These notes are electronically prepared by physicians and give a short report of the patient's hospital stay, including among other things information about his/her drugs and scheduled follow-up visits. The data were recorded retrospectivey and constituted part I of the study.

The medical records in hospital, including the discharge note, were electronical; however, the hospital medication charts were hand-written. There was no direct transfer of the hospital medication list to the discharge note. The discharge notes were addressed to the patient's GP, and mainly sent by post or, if possible, electronically transferred. The latter transfer method was, at the time of data collection, available for only a minority of the discharge notes.

In part II of the study, each individual patient's GP was visited $4-5$ months after the patient's discharge by the same pharmacist who conducted part I of the study. In the interview, the GP was asked to provide the patient's drug regimen and also report changes undertaken after discharge. The GP's information on medications was compared with the medication list given in the discharge note, of which the pharmacist had a copy. Medication changes carried out in the period after discharge were noted. The following were recorded: drugs used regularly or as required, drug doses, laboratory data (such as creatinine clearance and electrolytes), blood pressure and number of visits or re-admissions to hospital after discharge. It was also recorded whether and when the GP had received the discharge note relating to the hospitalisation in question.

For practical reasons, we chose to explore the postdischarge medications after 4-5 months. At this time, the GPs were supposed to have received the discharge note from the hospital and had had the possibility to call in patients in need of follow-up, in accordance with 
advice in the discharge note. Also, by this time, the patients might have contacted their GP because they needed more prescriptions as in general neither medication supply nor prescriptions are given from hospitals. However, drugs started during hospital stay are prescribed for a short period, usually for about 1-3 months. Thus, 4-5 months seemed to be an appropriate time, at which the majority of the patients would have been in contact with their GP.

\section{Statistical analysis}

A database was established and the data were analysed with SPSS V.19.0 for Windows. Descriptive statistics are given as means and SD for continuous variables and as frequencies for categorical variables. To test for differences between the group of patients that completed only part I and the group that completed both parts, an independent-sample $t$ test was used for continuous variables, and Pearson's $\chi^{2}$ tests was used for categorical variables. The Mann-Whitney test was used for variables that were not normally distributed, for example, length of stay. Comparisons were made between those patients who had undergone extensive drug changes and those who had fewer drug changes in parts I and II of the study. A patient was defined as having undergone extensive drug changes if he/she had experienced more than the mean number (the first whole number above the average) of drug changes per patient. The patients were treated as independent observations, as most GPs had only one patient in the study and there was no tendency that groups of patients could be linked to one specific GP.

The numbers of changes were not normally distributed, and it was difficult to achieve normally distributed residuals, even when standard transformations such as log-transformation were applied to this variable. Therefore, a logistic regression analysis was conducted instead, with the numbers of changes above/and below the mean number for all patients. This analysis was performed to determine the associations between extensive drug regimen changes in hospital (dependent variable) and the patient characteristics and number of drugs at admission (independent variables). A corresponding analysis of the extensive drug changes made in the postdischarge period (dependent variable) against the same independent variables was also performed, and also against the number of drugs used at discharge and whether or not the GP had received the patient discharge note. A multivariate explorative analysis of the abovementioned dependent and independent variables was also performed, where only variables with $p$ values less than $5 \%$ in the binary analysis were retained in the model. $\mathrm{p}$ Values of less than $0.05(\mathrm{p}<0.05)$ were considered statistically significant.

\section{RESULTS}

In total, 184 patients were included in the study, 105 of whom completed both parts I and II. The most common reason that 79 patients missed part II was that their GPs could not or did not want to schedule a meeting for an interview. Two patients died before follow-up.

The 105 patients who fulfilled both parts of the study were taking a total of 584 drugs (mean 5.6 drugs per patient) at admission, 29 of which were drugs taken as required (table 1). At discharge, these patients were taking 794 drugs (mean 7.6 per patient), 71 of which

Table 1 Patient characteristics, number of drugs used and number of drug changes in hospital and after discharge

\begin{tabular}{|c|c|c|}
\hline No. of patients & $\begin{array}{l}184 \\
\text { Per cent (SD) }\end{array}$ & $\begin{array}{l}105 \\
\text { Per cent (SD) }\end{array}$ \\
\hline \multicolumn{3}{|l|}{ Hospital stay } \\
\hline Gender: \% female & $55.4(3.6)$ & $54.3(4.9)$ \\
\hline Patients with heart failure & $23.4(3.1)$ & $17.1(3.8)$ \\
\hline Patients with GFR $<50 \mathrm{ml} / \mathrm{min}$ & $33.7(3.5)$ & $34.6(4.6)$ \\
\hline \multirow{2}{*}{$\begin{array}{l}\text { Patients with metabolic } \\
\text { disease }\end{array}$} & $26.8(3.3)$ & $27.6(4.4)$ \\
\hline & Mean (SD) [range]) & Mean (SD) [range] \\
\hline Age & $76.2(13.4)$ [22-98] & 76.1 (12.3) [41-95] \\
\hline $\begin{array}{l}\text { Length of stay at hospital } \\
\text { (days) }\end{array}$ & $11.2(11.8)[1-101)$ & $12.0(13.3)[1-101)$ \\
\hline Drugs on admission (all) & $6.2(3.8)[0-17]$ & 5.6 (3.6) [0-16] \\
\hline Drugs at discharge (all) & 8.2 (3.9) [1-20] & $7.6(3.5)[1-17]$ \\
\hline Drug changes at hospital & $4.6(2.7)[1-16]$ & $4.4(2.7)[1-16]$ \\
\hline \multicolumn{3}{|l|}{ After discharge } \\
\hline Drug changes after discharge & & 3.4 (2.9) [0-14] \\
\hline $\begin{array}{l}\text { Drug changes at hospital that } \\
\text { were changed again after } \\
\text { discharge }\end{array}$ & & $1.5(1.8)[0-13]$ \\
\hline
\end{tabular}


Table 2 Number of changes in drug regimens during hospital stay, and within 4-5 months after discharge from hospital

\begin{tabular}{|c|c|c|c|}
\hline & No. of drugs & Mean (SD) & Drug groups by ATC involved in changes (number of times) \\
\hline \multicolumn{4}{|c|}{ Changes during hospital stay } \\
\hline Start & 304 & $2.9(2.1)$ & $\begin{array}{l}\text { Antitrombotics B01A (56), betablocking agents C07A (18), } \\
\text { laxantia A06A (17), hypnotics N05C (16). Drugs most often } \\
\text { involved: acetylsalisylicacid, warfarin and metoprolol }\end{array}$ \\
\hline Dose adjustment & 66 & $0.6(0.9)$ & $\begin{array}{l}\text { Betablocking agents C07A (9), diuretics C03C (7), digitalis } \\
\text { glycosides C01A (6). Drugs most often involved: metoprolol and } \\
\text { loop-diuretics }\end{array}$ \\
\hline Stop & 95 & $0.9(1.2)$ & $\begin{array}{l}\text { Antitrombotics B01A (12), ACE inhibitors C09A/B (8), } \\
\text { betablocking agents C07A ( } 7) \text {, diuretics C03C (7). Drugs most } \\
\text { often involved: loop-diuretics and metoprolol }\end{array}$ \\
\hline \multicolumn{4}{|c|}{ Changes by GP after hospital stay } \\
\hline Start & 134 & $1.3(1.4)$ & $\begin{array}{l}\text { Opioid analgesics N02A (17), weak analgesics N02B (12). Drugs } \\
\text { most often involved: paracetamol and combination of codeine/ } \\
\text { paracetamol }\end{array}$ \\
\hline Dose adjustment & 73 & $0.7(1.1)$ & $\begin{array}{l}\text { Adrenergics for inhalation R03A (9), diuretics C03C (6), oral } \\
\text { glucocorticoids H02A (6). Drugs most often involved: metoprolol } \\
\text { and prednisolon }\end{array}$ \\
\hline Stop & 150 & $1.4(1.8)$ & $\begin{array}{l}\text { Antithrombotic agents B01A (14), hypnotics N05C (13), oral } \\
\text { glucocorticoids H02A (11). Drugs most often involved: zopiclone } \\
\text { and prednisolon }\end{array}$ \\
\hline
\end{tabular}

were drugs taken as required (table 1). There was no statistically significant difference between the 79 patients who missed part II and the 105 patients who completed both parts of the study in terms of their sex, age or lengths of stay. However, the 79 patients who did not complete the study used more drugs (regularly and as required) than those patients who completed both parts both at admission (mean 7.0 vs 5.6 drugs per patient, respectively, $\mathrm{p}=0.01,95 \%$ CI 0.33 to 2.55 ) and at discharge (mean 9.0 vs 7.6 drugs per patient, respectively, $\mathrm{p}=0.01,95 \%$ CI 0.35 to 2.59$)$. Heart failure was also recorded more often among these patients $(31.6 \%$ vs $17.1 \%$ of patients, respectively, $\mathrm{p}=0.02$ ).

At discharge, the 105 patients, who completed both parts of the study, had undergone 465 changes in their drug regimens, a mean of 4.4 changes per patient relative to their drug regimens at admission (table 1). Eighty $(76.2 \%)$ of the 105 patients had undergone three or more drug changes during their hospital stays. Table 2 shows types and numbers of drug changes and also the drugs most often involved in changes both at the hospital and at the follow-ups with the GPs.

A total of 88 different GPs were interviewed about the drug regimens for the 105 patients. Only13 of the GPs had more than 1 patient in the study: one had 4 patients, 2 had 3 patients and 10 GPs had 2 patients.

Drug regimen changes were made after discharge for 90 of the 105 patients, and $57(54.3 \%)$ underwent three or more drug changes, at their GPs. Of the 465 drug changes undertaken in hospital, $153(32.9 \%)$ were changed again after discharge (mean 1.5 per patient; table 3 ).
We assessed the OR for extensive drug changes $(\geq 5$; table 1) during hospitalisation with a logistic multivariate analysis, and $39.1 \%$ of the patients had underwent this

Table 3 Types of changes performed during hospital stay and the fate of these changes 4-5 months after discharge*

\begin{tabular}{|c|c|c|}
\hline $\begin{array}{l}\text { Type of change } \\
\text { performed at } \\
\text { hospital }\end{array}$ & $\begin{array}{l}\text { Results after } 4-5 \\
\text { months }\end{array}$ & $\begin{array}{l}\text { Number of } \\
\text { patients* (\%) } \\
\text { (Number of } \\
\text { drugs) }(\%)\end{array}$ \\
\hline Starting new drugs & $\begin{array}{l}\text { Discontinuation of } \\
\text { the drug }\end{array}$ & $44(46.3 \%)$ \\
\hline \multirow{3}{*}{$\begin{array}{l}95 \text { patients (304 } \\
\text { drugs) }\end{array}$} & & (86) (28.3) \\
\hline & Changing dose & $\begin{array}{l}15(15.8) \\
(18)(5.9)\end{array}$ \\
\hline & No change & $\begin{array}{l}86(90.5) \\
(200)(65.8)\end{array}$ \\
\hline \multirow[t]{3}{*}{$\begin{array}{l}\text { Changing dose } \\
45 \text { patients ( } 66 \text { drugs) }\end{array}$} & Discontinuation & $\begin{array}{l}11(24.4) \\
(13)(19.7)\end{array}$ \\
\hline & Changing dose & $\begin{array}{c}14(31.1) \\
(15)(22.7)\end{array}$ \\
\hline & No change & $\begin{array}{l}26(57.8) \\
(38)(57.6)\end{array}$ \\
\hline \multirow[t]{2}{*}{$\begin{array}{l}\text { Discontinuations } \\
58 \text { patients ( } 95 \text { drugs) }\end{array}$} & Started again & $\begin{array}{l}14(24.1) \\
(21)(22.1)\end{array}$ \\
\hline & No change & $\begin{array}{l}47(81.0) \\
(74)(77.9)\end{array}$ \\
\hline
\end{tabular}


Table 4 Associations between extensive drug changes, $\geq 5$ in hospital and $\geq 4$ after discharge, and various variables

\begin{tabular}{|c|c|c|c|c|c|c|}
\hline \multicolumn{7}{|c|}{ Dependent variable: $\geq 5$ changes in drug regimen versus fever drug changes during hospital stay } \\
\hline & \multicolumn{3}{|c|}{ Univariate } & \multicolumn{3}{|c|}{ Multivariate } \\
\hline & $\begin{array}{l}p \\
\text { Values }\end{array}$ & OR & $95 \% \mathrm{Cl}$ & -p Values & OR & $95 \% \mathrm{Cl}$ \\
\hline Gender (female $=1$, male $=0$ ) & 0.02 & 2.60 & 1.14 to 5.91 & 0.04 & 2.59 & 1.04 to 6.45 \\
\hline Age & 0.95 & 1.00 & 0.97 to 1.03 & ns & & \\
\hline Length of stay & 0.01 & 1.06 & 1.02 to 1.11 & 0.01 & 1.08 & 1.02 to 1.13 \\
\hline No.of drugs* at admission & 0.51 & 1.04 & 0.93 to 1.16 & ns & & \\
\hline Reduced renal function $(\mathrm{CrCl}<; 50 \mathrm{ml} / \mathrm{min})(\mathrm{no}=1$, yes $=0)$ & 0.08 & 2.09 & 0.91 to 4.78 & ns & & \\
\hline Heart failure (yes $=1$, no $=0$ ) & 0.99 & 0.99 & 0.35 to 2.81 & ns & & \\
\hline \multicolumn{7}{|c|}{ Dependent variable: $\geq 4$ changes in drug regimen vs fever drug changes at the follow-up visit at GP } \\
\hline Gender (female $=1$, male $=0$ ) & 0.66 & 1.19 & 0.55 to 2.60 & ns & & \\
\hline Age & 0.89 & 1.00 & 0.97 to 1.04 & ns & & \\
\hline Length of stay & 0.27 & 1.02 & 0.99 to 1.05 & ns & & \\
\hline Number of drugs* at admission & 0.00 & 1.34 & 1.16 to 1.54 & ns & & \\
\hline No.of drugs* at discharge & 0.00 & 1.41 & 1.21 to 1.64 & 0.02 & 1.29 & 1.04 to 1.59 \\
\hline No.of drug changes at hospital & 0.04 & 1.18 & 1.01 to 1.38 & ns & & \\
\hline $\begin{array}{l}\text { Discharge note received within the time of follow-up } \\
(1=\text { no, } 1=\text { yes })\end{array}$ & 0.45 & 1.51 & 0.52 to 4.41 & ns & & \\
\hline Reduced renal function $(\mathrm{CrCl}<; 50 \mathrm{ml} / \mathrm{min})(\mathrm{no}=1$, yes $=0)$ & 0.64 & 1.22 & 0.54 to 2.75 & ns & & \\
\hline Heart failure $($ yes $=1$, no $=0$ ) & 0.78 & 0.86 & 0.30 to 2.43 & ns & & \\
\hline
\end{tabular}

many changes. The incidence of extensive changes increased significantly with female sex $(\mathrm{OR}=2.59,95 \%$ CI 1.04 to 6.45$)$ and length of stay $(\mathrm{OR}=1.08,95 \% \mathrm{CI}$ 1.02 to 1.13 ) whereas age, the number of drugs at admission and comorbidities showed no association (table 4). Furthermore, the OR for extensive drug changes after discharge $(\geq 4$ changes; table 1$), 41.9 \%$ of the patients underwent these many changes, increased significantly with the number of drugs used at discharge from hospital $(\mathrm{OR}=1.29,95 \%$ CI 1.04 to 1.59$)$.

Among the 105 discharge notes prepared for these patients, only 68 included a complete medication list, and only 24 of the discharge notes were received by the GPs within 7 days. For 17 of the patients, the discharge note was not received by the GP at the time of follow-up visit.

\section{DISCUSSION}

This study has shown that extensive changes in drug regimens were made during these patients' hospital stays. This is not surprising because hospitalised patients are often seriously ill or are experiencing deteriorations in chronic diseases. It is noteworthy that three-quarters of the patients were discharged with at least three changes to their drug regimens relative to their drug regimens at admission. The addition of new drugs markedly exceeded the number of drug discontinuations. Other studies have also reported that drug regimens are

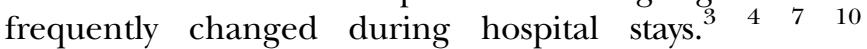
However, Himmel et $a \hat{l}^{3}$ did not state whether the changes were continued until discharge from hospital, and in a one-day survey, Karapinar $e t a l^{10}$ did not report whether these changes were maintained after discharge. Grimmsmann et $a l^{7}$ compared prescriptions during a 3-month period before admission and after discharge but did not relate the changes to the medication list at discharge. In comparison, we recorded changes that were to be continued after discharge. Information about drug regimen changes is a vital part of the patient transfer process from hospital into primary care, because many drug changes must be followed up and evaluated in the postdischarge period.

Of particular note is the finding that in addition to the extensive drug changes made during hospitalisation, almost equally extensive changes were made in the first months after the patients were discharged from hospital (3.4 vs 4.4 drug changes per patient, respectively). There are several reasons for this, one of which is poor communication between hospitals and GPs. An unsatisfactory delay in the receipt of discharge notes is part of this problem. GPs received the patients' discharge notes within a week for only a quarter of the patients whose drug regimens were altered by the GP. The non-appearance of information from the hospital might lead the GP to change the patient's drug regimen at his/her own discretion, a view supported by Kriplani et al. ${ }^{11}$ In the 1996 study by Himmel et $\mathrm{al}^{4}$ GPs received discharge letters for only 5 of 130 patients, illustrating how difficult it may be to maintain a patient's drug list. Although our findings showed some improvement, this issue is still highly relevant 15 years later.

Besides their timeliness, the content and quality of the discharge notes will affect how the patients' drug regimes 
are followed up after discharge. ${ }^{10-13}$ We found that only 68 of the 105 discharge notes contained complete drug lists. The missing information might explain, at least in part, the extensive postdischarge drug changes.

Another reason that GPs changed their patients' medications might be that the hospital changes were in response to an acute illness, so after stabilisation in primary care, the changes were no longer relevant. In such cases, this reversal is well founded. Our finding that about one-third of the changes made in hospital were changed again in the context of primary care supports this explanation.

In this study, we looked for factors that predicted extensive drug changes. We did not identify major predictors, although female sex and length of hospital stay were associated with extensive changes in hospital, and the number of drugs at discharge was associated with extensive changes after discharge. The latter association, more specifically, an association between in-hospital changes and changes made 1 month after discharge has also been reported by others, ${ }^{5}$ and is consistent with the results of our univariate regression analysis.

Differences in the healthcare systems of various countries, together with differences in health incentives and audits in relation to the prescription of drugs, imply that studies should be compared with caution. ${ }^{4}$ Therefore, the topic of drug regimen changes related to the transfer of patients between different levels of care should be explored within various specific healthcare settings.

We did not scrutinise in depth the types of drugs involved in these drug changes. However, the most common medications that were altered in hospital were those for the treatment of a new disease, or deterioration of an existing disease, whereas the changes made at the GPs most commonly involved drugs for the relief of symptoms, such as hypnotics and analgesics. This difference is a natural reflection of the organisation of the healthcare system wherein GPs are expected to care for the whole patient, whereas hospital specialists concentrate on emergency situations and specialised medicine.

Health professionals, as well as the patients themselves, should be aware that drug regimens are most likely to be adjusted or even changed profoundly during transfer between different levels of care. Maximum efforts should be made to inform all the parties involved about all drug changes. In essence, this is about creating a culture of efficient and trustworthy communication between levels of care. Health professionals, health authorities and patients all have roles to play in this task.

A limitation of our study is that we were unable to visit the GPs of all patients after their discharge. The patients who completed only part I were very similar to those who also completed part II in the terms of their characteristics and drug use, except that the former group used more drugs on admission and at discharge. Consequently, the drug regimen of those patients might have been altered more extensively by the GPs, so an underestimation of the number of drug changes cannot be ruled out. Furthermore, it is a limitation that although categories of drug changes were investigated, the justification for the individual changes was not evaluated. Another limitation is related to the accuracy of the information on the patients' medication at admission to hospital. The collection of data was based on the recordings done by the physicians. It is a possibility that these data may have been inaccurate and accordingly this would have had consequences for the further evaluations. A standard reconciliation process had not been introduced in Norway at the time the data were collected, but it has later come into use.

A strength of our study was its multicentre design, ensuring the inclusion of patients of all ages (18 years or more), with a wide range of diagnoses. Thus, our findings could be widely generalisable to patients transferred between primary and secondary care within our healthcare system. We did not include changes made to accommodate the specific drug lists of the participating hospitals or generic changes. Their inclusion would have entailed a higher total number of changes, and such changes might have been reversed again in primary care. Moreover, in general, these changes are not associated with impaired treatment, although they may sometimes cause confusion, with the risk of double treatment. Another strength of this study was that we visited the GPs and interviewed them about the drug regimen of each individual patient. This allowed hands-on observation of the information flow. To our knowledge, this time-consuming, but important, approach has been rarely used by other researchers.

\section{CONCLUSIONS}

In addition to the extensive changes in drug regimens made during hospitalisation, almost equally extensive changes were made in the first months after the patients were discharged from hospital. Surveillance of drug regimens is particularly necessary when patients are moving between levels of care, especially in the period immediately after hospital discharge. The implementation of an optimal communication system should be given high priority.

\section{Author affiliations}

${ }^{1}$ Diakonhjemmet Hospital Pharmacy, Diakonhjemmet Hospital, Oslo, Norway ${ }^{2}$ Department of Pharmaceutical Biosciences, School of Pharmacy, University of Oslo, Oslo, Norway

${ }^{3}$ Department of Pharmacoepidemiology, Norwegian Inst of Public Health, Oslo, Norway

${ }^{4}$ Department of Pharmacology, Institute of Clinical Medicine, Faculty of Medicine, University of Oslo and Oslo University Hospital, Rikshospitalet, Oslo, Norway, Oslo, Norway

${ }^{5}$ Lovisenberg Hospital Pharmacy, Lovisenberg Hospital, Oslo, Norway

${ }^{6}$ Pharmaceutical Services, Hospital Pharmacies HF, Oslo, Norway

${ }^{7}$ Department of Health Management and Health Economics, University of Oslo, Oslo, Norway

${ }^{8}$ Department of Biostatistics, University of Oslo, Oslo, Norway

Acknowledgements We thank members of the healthcare teams in the participating departments and the general practitioners who participated in the interviews. 
Contributors All the authors have given (1) substantial contributions to conception and design, acquisition of data, or analysis and interpretation of data; (2) drafting the article or revising it critically for important intellectual content and (3) final approval of the version to be published.

Funding The study was supported by grants from the Norwegian Directorate of Health given in a letter dated 8 October 2007 (no grant number).

Competing interests None.

Patient consent Obtained.

Ethics approval The study was approved by the Norwegian Regional Committee for Medical Research and the Norwegian Social Science Data Services.

Provenance and peer review Not commissioned; externally peer reviewed.

Data sharing statement There are no additional data available.

\section{REFERENCES}

1. Kruse W, Rampmaier J, Frauenrath-Volkers C, et al. Drug-prescribing patterns in old age. A study of the impact of hospitalization on drug prescriptions and follow-up survey in patients 75 years and older. Eur J Clin Pharmacol 1991;41:441-7.

2. Beers $\mathrm{MH}$, Dang J, Hasegawa J, et al. Influence of hospitalization on drug therapy in the elderly. J Am Geriatr Soc 1989;37:679-83.

3. Himmel W, Kochen MM, Sorns U, et al. Drug changes at the interface between primary and secondary care. Int J Clin Pharmacol Ther 2004;42:103-9.
4. Himmel W, Tabache M, Kochen MM. What happens to long-term medication when general practice patients are referred to hospital? Eur J Clin Pharmacol 1996;50:253-7.

5. Mansur N, Weiss A, Beloosesky Y. Relationship of in-hospital medication modifications of elderly patients to postdischarge medications, adherence, and mortality. Ann Pharmacother 2008;42:783-9.

6. Cochrane RA, Mandal AR, Ledger-Scott M, et al. Changes in drug treatment after discharge from hospital in geriatric patients. BMJ. 1992;305:694-6.

7. Grimmsmann T, Schwabe U, Himmel W. The influence of hospitalisation on drug prescription in primary care-a large-scale follow-up study. Eur J Clin Pharmacol 2007;63:783-90.

8. WHO Collaborating Centre for Drug Statistics Methodology. ATC classification index with DDDs. Oslo: WHO Collaborating Centre, 2010. http://www.whocc.no/atc_ddd_index/(accessed 25 Jan 2012).

9. Blix HS, Viktil KK, Reikvam A, et al. The majority of hospitalised patients have drug-related problems: results from a prospective study in general hospitals. Eur J Clin Pharmacol 2004;60:651-8.

10. Karapinar F, van den Bemt PM, Zoer J, et al. Informational needs of general practitioners regarding discharge medication: content, timing and pharmacotherapeutic advice. Pharm World Sci 2010;32:172-8.

11. Kripalani S, LeFevre F, Phillips $\mathrm{CO}$, et al. Deficits in communication and information transfer between hospital-based and primary care physicians: implications for patient safety and continuity of care. JAMA 2007;297:831-41.

12. Glintborg B, Andersen SE, Dalhoff K. Insufficient communication about medication use at the interface between hospital and primary care. Qual Saf Health Care 2007;16:34-9.

13. Ahrens D, Behrens G, Himmel W, et al. Appropriateness of proton pump inhibitor recommendations at hospital discharge and continuation in primary care. Int J Clin Pract 2012;66:767-73. 